\title{
Fragmentación productiva, comercio exterior y complejidad estructural: análisis comparativo del Brasil y México ${ }^{1}$
}

\author{
Kaio Glauber Vital da Costa, Marta Reis Castilho \\ y Martín Puchet Anyul
}

\section{Resumen}

A partir de la década de 1980, en el Brasil y México se adoptaron estrategias comerciales y productivas divergentes, con importantes efectos en sus respectivas estructuras productivas y comerciales. En este estudio se investiga la manera en que los diferentes patrones de especialización comercial de los dos países incidieron en la complejidad de sus respectivas estructuras de producción entre 1995 y 2011. Se argumenta que, si bien los patrones de comercio exterior del Brasil y México difieren principalmente en cuanto a sus estructuras de exportación, los procesos de apertura comercial y de inserción en las cadenas globales de valor llevaron a una reducción de la complejidad de la red de interrelaciones entre los sectores. Dado que estos países constituyen las dos mayores economías de América Latina, la reducción de la complejidad de sus estructuras productivas no solo tiene repercusiones en la dinámica de sus respectivas economías nacionales, sino también en la de las demás economías de la región.

\section{Palabras clave \\ Desarrollo económico, estrategias del desarrollo, comercio exterior, política comercial, especialización de la producción, productividad, exportaciones, importaciones, análisis comparativo, Brasil, México}

\section{Clasificación JEL}

$\mathrm{F} 1,014, \mathrm{C} 67, \mathrm{~F} 14,054$

\section{Autores}

Kaio Glauber Vital da Costa es Profesor Adjunto e investigador del Grupo de Industria y Competitividad del Instituto de Economía de la Universidad Federal de Río de Janeiro. Correo electrónico: kaio.economia@gmail.com.

Marta Reis Castilho es Profesora Asociada y Coordinadora del Grupo de Industria y Competitividad del Instituto de Economía de la Universidad Federal de Río de Janeiro. Correo electrónico: castilho@ie.ufrj.br.

Martín Puchet Anyul es Profesor Titular de Métodos Cuantitativos en la Facultad de Economía de la Universidad Nacional Autónoma de México (UNAM). Correo electrónico: anyul@unam.mx.

\footnotetext{
Se agradecen los comentarios realizados por un colaborador anónimo de esta Revista que contribuyeron en gran medida a la presente versión de este artículo. La investigación de la que deriva este artículo fue parcialmente financiada por la Coordinación de Perfeccionamiento de la Enseñanza Superior (CAPES), un órgano del Ministerio de Educación (MEC) del Brasil, por medio de su Programa Nacional de Posdoctorado (PNPD), del que Kaio Costa fue becario, y del Programa Profesor Visitante en el Exterior (PVEx), que hizo posible la estadía de Marta Castilho en la Universidad Complutense de Madrid durante el año académico 2018/19.
} 


\section{Introducción}

El crecimiento económico sostenido requiere una transformación de la estructura productiva compatible con la evolución de la demanda interna y los cambios en el comercio internacional. Esto significa que la estructura productiva de un país debe ser capaz de adaptarse a las transformaciones en curso en el ámbito interno y externo (Chenery, 1980). En las dos últimas décadas, las estructuras productivas y los patrones de comercio internacional del Brasil y México, las dos mayores economías de América Latina, experimentaron profundas transformaciones. Estos cambios tuvieron efectos directos en la organización y la intensidad de las articulaciones entre los sectores, de manera que ambas estructuras productivas perdieron complejidad estructural a partir de mediados de la década de 1990 (Coutinho, 1997; Britto, 2002; Moreno-Brid y Ros, 2010).

Desde la década de 1980, el agotamiento del modelo de industrialización por sustitución de importaciones, basado en el crecimiento del mercado interno, llevó a las economías latinoamericanas a avanzar hacia nuevos patrones de especialización productiva y comercio exterior. Como consecuencia de esas modificaciones, se consolidaron dos grandes patrones de especialización productiva y comercial. El primero tiene su epicentro en el Cono Sur, con países (como el Brasil) que presentan una preponderante especialización en sectores industriales procesadores de recursos naturales, que también son sectores de alta intensidad de capital. El segundo corresponde a México y otros países de Centroamérica, que presentan un modelo alternativo de especialización productiva y comercial, basado en la maquila electrónica, automotriz y textil, dirigida principalmente al mercado de los Estados Unidos (Katz, 2000).

A pesar de las diferentes especializaciones, el comercio exterior de las dos mayores economías de América Latina presenta algunas similitudes. El Brasil y México muestran, por una parte, una creciente dependencia de los insumos intermedios importados y, por otra, exportaciones con baja capacidad de generación de empleo e ingresos (Ruiz-Nápoles, 2004; Fujii y Cervantes, 2013; Kupfer y otros, 2013). El gran incremento de la importación de insumos en los años noventa y a lo largo de la década de 2000 estaría relacionado con los procesos de apertura comercial, la persistente apreciación del tipo de cambio y las estrategias microeconómicas de localización de las plantas industriales de las empresas transnacionales.

El proceso de fragmentación productiva y la consiguiente formación de cadenas globales de valor parecen haber exacerbado los patrones de especialización comercial de ambos países. Pese a las diferentes posiciones y niveles de participación de los dos países en las cadenas globales de valor (Hermida, 2016; Boddin, 2016), sus respectivas inserciones en esas cadenas no lograron modificar sus patrones de comercio exterior (Medeiros y Trebat, 2018). Los sectores tradicionalmente exportadores - en el Brasil, aquellos basados en los recursos naturales (intensivos en capital) y, en México, las maquilas (intensivos en mano de obra) - reforzaron la contribución de los respectivos sectores predominantes al total de las exportaciones y al saldo comercial. Por otra parte, los sectores con un mayor contenido tecnológico se volvieron cada vez más deficitarios y dependientes de los insumos intermedios importados (Katz, 2000).

El surgimiento de cadenas de producción y valor mundiales y regionales cambió drásticamente la organización de la producción mundial de bienes y servicios desde mediados de la década de 1980 (Baldwin, 2011), provocando efectos más profundos y duraderos en los patrones de comercio internacional y de inversión. La división internacional de la producción forma parte desde hace tiempo del comercio internacional, pues los países importan bienes manufacturados que se incorporarán a sus exportaciones (Athukorala y Menon, 2010). Sin embargo, la reducción de los costos del transporte y las comunicaciones, la aceleración del progreso tecnológico (que permitió compartir y flexibilizar el proceso productivo) y la reducción de las barreras económicas y políticas al comercio aumentaron las 
oportunidades para la fragmentación internacional de la producción. El cambio en la gobernanza de las empresas industriales a partir de la década de 1980, que supuso su financierización, "incentivó" este movimiento al considerarlo una forma de reducir los costos y, por consiguiente, aumentar los beneficios y dividendos (Sarti e Hiratuka, 2018).

En este contexto, la profundización de la fragmentación productiva, con la creciente incorporación de los países en desarrollo, condujo a una redefinición de la división internacional del trabajo, que está cambiando la geografía de la producción mediante la deslocalización de determinadas industrias. Este proceso está orientado principalmente por dos factores: i) las políticas de apertura comercial, como la firma de acuerdos regionales, y ii) los avances en las tecnologías de la información y las comunicaciones. El primer factor se tradujo en la reducción de los aranceles y la disminución de los obstáculos a la inversión extranjera directa. El segundo factor disminuyó los costos de transporte y de coordinación y supervisión de las actividades dentro de las empresas transnacionales. En consecuencia, las empresas transnacionales comenzaron a reorientar sus estrategias de localización de las industrias según las características de cada región o país, incluidos los costos de la mano de obra, el tamaño del mercado interno o los aspectos regulatorios e institucionales. La reducción de los costos de localización en el exterior, debido a la internacionalización de la producción, llevó a las empresas transnacionales a trasladar algunas plantas de países altamente desarrollados a países en desarrollo, con menores costos de producción.

El objetivo del presente estudio es analizar la complejidad de las estructuras productivas del Brasil y México en un contexto de procesos productivos fragmentados. En este estudio, una estructura más compleja significa una mayor interdependencia entre los sectores y, por lo tanto, una mayor circularidad de los flujos de bienes y servicios en esas economías. La utilización de un indicador de complejidad estructural, que tenga en cuenta toda la red de interrelaciones, directas e indirectas, entre los sectores permite comprender mejor las estructuras productivas de las dos mayores economías de América Latina. Los estudios comparativos de las economías brasileña y mexicana son escasos, de manera que el presente análisis también contribuye a las investigaciones comparativas entre las dos economías.

El artículo se divide en tres secciones además de esta introducción. En la segunda sección se desarrollan los elementos conceptuales relacionados con el proceso de fragmentación productiva y la complejidad estructural, en la tercera sección se presentan los resultados y la cuarta sección corresponde a las conclusiones.

\section{Fragmentación productiva y complejidad estructural: revisión de la literatura y consideraciones conceptuales}

Los procesos de apertura comercial por los que pasaron el Brasil y México entre las décadas de 1980 y 1990 dieron lugar a dos patrones distintos de especialización comercial. Por una parte se encuentran el Brasil y los demás países de América del Sur especializados en la exportación de productos basados en recursos naturales y, por otra, México, con un patrón exportador centrado en las maquilas industriales destinadas en gran parte a los Estados Unidos (Katz, 2000). Además de este efecto en las exportaciones, la apertura comercial impulsó movimientos de reestructuración industrial en los dos países, que se reflejaron en una mayor dependencia de los insumos intermedios importados en casi todos los sectores. El aumento relativo a las partes, piezas y componentes estaría relacionado con las estrategias defensivas de las empresas nacionales frente a la competencia extranjera y con la utilización de la red de proveedores extranjeros por las empresas transnacionales (Britto, 2002; Kupfer, 2005; Fujii y Cervantes, 2013). 
El resultado de la mayor dependencia de los insumos importados sería un creciente debilitamiento de la estructura productiva. Ese debilitamiento estaría vinculado con la pérdida de eslabones en varias cadenas productivas, que disminuiría la densidad de la matriz de interrelaciones industriales. Si esa matriz se imagina como una red de intercambios entre $n$ sectores, en la que los sectores (vértices) están articulados por arcos (flujos de bienes y servicios), la menor densidad puede entenderse como la desaparición de varios de esos arcos o flujos. En esta analogía con la teoría de grafos, cuando una economía se vuelve más compleja, en el sentido de que cada sector necesita cada vez más de otros sectores como proveedores de insumos para producir, la demanda intermedia crece como proporción del producto total y la probabilidad de encontrar trayectorias o caminos que colapsan en los circuitos también crece. En otras palabras, el debilitamiento de la estructura productiva está relacionado con un menor nivel de interdependencia entre los sectores.

Como señalan Romero, Dietzenbacher y Hewings (2009), ante los efectos de la fragmentación espacial de la producción, es necesario tener en cuenta dos casos, pues algunas áreas (regiones o países) pueden perder determinadas etapas, tareas, actividades o eslabones que componen el proceso productivo, mientras otras pueden atraerlas. Desde el punto de vista de los países que pierden esas etapas, la fragmentación podría provocar una disminución de la complejidad de sus sistemas productivos, debido al traslado de algunos o varios encadenamientos internos a otros países. Las consecuencias de esta fragmentación en países con niveles de industrialización relativamente avanzados podrían ser significativas y eventualmente provocar un proceso de "vaciado" (hollowing out) (Hewings y otros, 1998; Guo, Hewings y Sonis, 2005). Como resultado de la fragmentación, la dependencia de esos países de los insumos importados del resto del mundo aumenta.

En contraste, desde el punto de vista de los países que reciben esas etapas productivas, la fragmentación de la producción podría aumentar la complejidad estructural. Sin embargo, sería necesario que-además de la fragmentación- se crearan encadenamientos entre las empresas recién instaladas, en general empresas transnacionales, y las empresas nacionales. En un caso extremo de lo que podría denominarse "sectores de enclave", cuando la demanda intermedia de las nuevas empresas se dirige a los insumos importados, generando pocos encadenamientos con la economía nacional, la hipótesis de que la fragmentación podría aumentar la complejidad estructural puede no verificarse. Los sectores de enclave operan en los países en desarrollo con miras a desarrollar fases específicas de los procesos productivos que presentan un alto nivel de intensidad tecnológica. Los insumos intermedios necesarios se compran en el exterior y el producto se utiliza en actividades manufactureras sucesivas en plantas localizadas en otros países.

\section{La complejidad estructural como aspecto particular de la articulación interindustrial}

Una economía moderna se caracteriza por una red de sectores o unidades productivas intrínsecamente ligadas entre sí, que dependen cada vez más de los insumos intermedios proporcionados por diversos sectores de la economía. La complejidad de una economía se considerará conceptualmente como el resultado del proceso de desarrollo que aumenta la multiplicidad de interacciones económicas dentro del sistema económico (Sonis y Hewings, 1998). Esta perspectiva está estrechamente relacionada con los análisis realizados por autores estructuralistas, como Albert Hirschman, Hollis Chenery, Celso Furtado y Arthur Lewis, entre otros. Para esos autores, el proceso de desarrollo de los países se caracterizaría por el aumento de las interacciones que tienen lugar entre los sectores productivos de una economía. En otras palabras, el desarrollo económico estaría acompañado por la intensificación de las interacciones entre los sectores productivos, y no solo por la asignación de recursos entre esos sectores. 
La complejidad es un fenómeno multidimensional con varios enfoques y múltiples definiciones, que no se examinarán en detalle en esta sección (Adami, 2002). La noción de complejidad, que tuvo origen en la física y la biología, se extendió al análisis de los sistemas sociales y económicos (Arthur, 1999; Rosser, 2012; Durlauf, 2005). Como señala Fontana (2008), la perspectiva de la complejidad aplicada a la economía supone, en comparación con la visión dominante (economía ortodoxa o convencional), una percepción radicalmente diferente de la naturaleza de los fenómenos económicos. Esto se debe a que un sistema complejo se caracteriza por la presencia de un gran número de agentes heterogéneos que interactúan entre sí, la ausencia de un controlador global, la adaptación por medio del aprendizaje y la evolución y la importancia del análisis fuera del equilibrio. Además, de acuerdo con Sonis y Hewings (1998), aunque la noción de complejidad haya surgido a partir del análisis de las dinámicas no lineales de las ciencias naturales, esta noción puede ser importante para analizar aspectos del desarrollo económico de los países, incluso en el caso de análisis económicos con sistemas de ecuaciones lineales, como en el enfoque de insumo-producto.

La definición de Simon (1962) de un sistema complejo es compartida por varios autores que analizan la complejidad de las economías. Simon (1962) define un sistema complejo como aquel compuesto por un gran número de partes que interactúan de manera no trivial. En dichos sistemas, el todo es mayor que la suma de las partes en el sentido de que, dadas las propiedades de las partes y las leyes que gobiernan sus interacciones, no es fácil inferir las propiedades de la estructura completa. En el enfoque elaborado por Simon (1962), un sistema complejo está compuesto por subsistemas que, a su vez, tienen sus propios sistemas, y así sucesivamente. Esto significa que la complejidad también se caracteriza por las jerarquías entre los subsistemas, pues los diferentes subsistemas tienen diferentes influencias en la dinámica general del sistema. En el análisis de la complejidad aplicada a la economía, estas características son de fundamental importancia.

Los indicadores presentados en el cuadro 1 muestran la manera en que se aborda el fenómeno de la complejidad estructural o económica de un país a partir de diferentes enfoques metodológicos. La interdependencia o conectividad entre los diversos sectores productivos es una característica crucial del análisis económico. Se han realizado diversas propuestas para su medición, empezando por las medidas clásicas de interdependencia directa de Chenery y Watanabe (1958) y las medidas de enlaces totales (hacia adelante y hacia atrás) desarrolladas por Rasmussen (1963) y Hirschman (1961). Algunas contribuciones particularmente útiles para el estudio de la complejidad en una estructura son aquellas que ofrecen medidas sumarias u "holísticas", que captan la multiplicidad de conexiones o interdependencias entre sectores en un único número, que facilita las comparaciones históricas e internacionales (o interregionales) de las estructuras de producción de las economías.

Uno de los primeros ejemplos es el porcentaje de coeficientes técnicos diferentes de cero desarrollados por Peacock y Dosser (1957). Los índices de interdependencia de Yan y Ames (1965) y la matriz de rondas de transacción (transaction rounds matrix) de Robinson y Markandya (1973) son algunos intentos más elaborados de cuantificar la interdependencia de esa manera. Como medida de conectividad, Jensen y West (1980) sugirieron las sumas medias de filas o columnas de la matriz de coeficientes técnicos, A. A partir de esos estudios iniciales, diversos autores (Finn, 1976; Ulanowicz, 1983) construyeron otros indicadores para el análisis de los sistemas ecológicos, que posteriormente se utilizaron en el análisis económico. Más adelante, Basu y Johnson (1996) propusieron una nueva medida basada en la teoría de grafos dirigidos y en el análisis de trayectorias estructurales (structural path analysis) sobre la base de cuadros de insumo-producto, y Sonis y Hewings (1998) utilizaron un método similar. Por último, Romero, Dietzenbacher y Hewings (2009) elaboraron un indicador de complejidad estructural de las economías a partir del método de longitudes medias de propagación, que busca medir el tamaño de la cadena de producción de los sectores o la distancia de los sectores con respecto a la demanda final. 


\section{Cuadro 1}

Indicadores de complejidad

\begin{tabular}{|c|c|}
\hline Peacock y Dosser (1957) & $\frac{100}{n^{2}} i^{\prime} K i$ \\
\hline Chenery y Watanabe (1958) & $\frac{i^{\prime} A x}{i^{\prime} x}$ \\
\hline Rasmussen (1963) y Hirschman (1961) & $\frac{1}{n} i^{\prime}(I-A)^{-1} i$ \\
\hline Yan y Ames (1965) & $\frac{100}{n^{2}} \sum_{i, j} \frac{1}{0_{i j}^{Y A}}$ \\
\hline Lantner (1972 y 1974) & $\frac{(1-\Delta)}{\Delta}$ \\
\hline Robinson y Markandya (1973) & $T_{i j}=\left\{\begin{array}{c}t_{j} \text { si } A_{i j} \neq 0 \\
0 \text { si } A_{i j}=0\end{array}\right.$ \\
\hline Finn (1976) y Ulanowicz (1983) & $\frac{i^{\prime} x i}{i^{\prime} y}$ \\
\hline Jensen y West (1980) & $\frac{1}{n} i^{\prime} A i$ \\
\hline Dietzenbacher (1992) & $\lambda=$ autovalor dominante \\
\hline Romero, Dietzenbacher y Hewings (2009) & $L(L-1)$ \\
\hline Amaral, Dias y Lopes (2007) & $G(A) H(A)$ y $G(L) H(L)$ \\
\hline Hausmann y otros (2014) & $\begin{array}{c}k_{c, 0}=\sum_{p=1}^{N_{p}} M_{c p} \text { (diversificación) y } \\
k_{p, 0}=\sum_{c=1}^{N_{c}} M_{c p} \text { (ubicuidad) }\end{array}$ \\
\hline
\end{tabular}

Donde:

A : matriz de coeficientes técnicos

$x \quad$ : vector de producción

i : vector de suma

n $\quad$ : número de sectores

I : matriz de identidad

$K \quad$ : matriz booleana

$\Delta \quad$ : determinante de la matriz $(I-A)$

$0_{i j}^{Y A} \quad$ : matriz de orden (order matrix)

$\lambda \quad$ : autovalor dominante de la matriz $A$

y $\quad$ : demanda final

$L \quad$ : matriz inversa de Leontief

$T_{i j} \quad$ : matriz de rondas de transacción

En algunos estudios más recientes se volvió a poner el cambio estructural al centro de la comprensión del desarrollo económico de los países (Hausmann e Hidalgo, 2011). Las diferencias en la capacidad de los países para perfeccionar su estructura productiva y diversificar sus exportaciones en productos más complejos parecen contribuir a explicar las diferencias en sus niveles de desarrollo 
(McMillan y Rodrik, 2011)2. De acuerdo con Hausmann e Hidalgo (2011), la capacidad de crecimiento económico de un país se relaciona con la diversidad de sus capacidades, visto que se necesitan diferentes tipos de capacidades para avanzar hacia nuevas actividades asociadas con mayores niveles de productividad. Un resultado empírico bien establecido es que los países especializados en productos más sofisticados crecen con mayor rapidez (Rodrik, 2006; Hausmann, Hwang y Rodrik, 2007).

La metodología del espacio-producto desarrollada por Hidalgo y otros (2007) estudia los cambios en la posición histórica de los países dentro del espacio-producto en evolución. Este espacio-producto es una representación de las distancias entre las estructuras de flujos de comercio internacional para todos los productos. El posicionamiento histórico de los países en este espacio-producto utiliza índices específicos de ventajas comparativas reveladas. Los autores insertan estos índices en un argumento teórico basado en la noción de capacidad de los países: la complejidad de la estructura productiva nacional determina el potencial del país para promover su propio desarrollo. Sin embargo, los indicadores que utilizan se basan en las características de las exportaciones de los países, lo que puede representar una limitación o inexactitud para aquellos países que tienen estructuras de exportación muy diferentes de su estructura productiva ${ }^{3,4}$.

Recientemente, Lantner y Carluer (2004) y Lantner y Lebert (2013 y 2015) siguieron un camino diferente, al utilizar las propiedades de los determinantes de la matriz de Leontief para desarrollar una medida "sumaria" de interdependencia, sobre la base de los trabajos de Wong (1954) y Bott y Mayberry (1954). En el marco de ese enfoque de análisis de la complejidad económica y estructual de los países, Wong (1954) sugiere que el determinante de la matriz de coeficientes técnicos $\Delta=(I-A)$ es una medida relativa del volumen de la producción neta y de la complejidad del sistema productivo. El enfoque propuesto por Lantner (1972 y 1974) también parte de la interpretación de los determinantes de la matriz $(I-A)$, pero se basa en los teoremas propuestos por Bott y Mayberry (1954). A partir del estudio de los determinantes de las matrices de relaciones interindustriales o comerciales, Lantner (1972 y 1974), Gazon y Nihon (1976) y Lantner y Lebert (2013 y 2015) elaboran el concepto de circularidad estructural. El índice de circularidad estructural se utiliza para medir el nivel de interdependencia de un conjunto de industrias en un sistema económico o de países y regiones en el comercio internacional.

Desde el punto de vista cuantitativo, el determinante tiene la ventaja de ser un indicador sintético que muestra la organización interna de la estructura de los sectores productivos o de los vínculos comerciales entre regiones o países, es decir, la posición y la intensidad de las conexiones entre los sectores o países. Desde el punto de vista cualitativo, permite interpretar la complejidad de las estructuras productivas como resultado del proceso gradual de expansión de la red de interdependencias jerárquicas entre los sectores de la economía. Además, es posible realizar un análisis de descomposición estructural a partir del cálculo de los determinantes, de manera de calcular las tasas de interdependencia, dependencia y autarquía de las economías.

Formalmente, el índice de circularidad o complejidad estructural se define como ice $=\frac{(1-\Delta)}{\Delta}$. El índice de complejidad estructural es un indicador de la cantidad de circuitos de retroalimentación que existen entre los sectores de una economía. La presencia de circuitos de retroalimentación indica

2 El papel de las capacidades como condición previa para el crecimiento a largo plazo es central en los trabajos de Hirschman (1961), Lewis (1958), Rostow (1959) y Kaldor (1967). Estos autores describieron el desarrollo económico esencialmente como un proceso de transformación estructural y aumento de la productividad, impulsados por el fortalecimiento progresivo de las capacidades productivas.

3 Hausmann y otros (2014) proponen evaluar la sofisticación de las economías por medio de dos características de las exportaciones: la ubicuidad (o exclusividad) de los productos exportados por un país y la diversidad de productos de las exportaciones.

4 En un estudio sobre la economía brasileña en la década de 2000, Torracca (2017) muestra la manera en que difieren las estructuras de exportación y producción, lo que puede ocurrir en particular en economías ricas en recursos naturales y con una complejidad estructural relativamente avanzada. 
que las relaciones entre los sectores productivos son densas y que los sectores están integrados entre sí. La estructura productiva se vuelve más compleja y desarrollada a medida que aumenta el número de circuitos de retroalimentación en relación con todos los circuitos que unen a todos los sectores (Puchet, 1996).

Cuando una estructura productiva se vuelve más compleja, en el sentido de que cada sector depende cada vez más de los demás sectores como proveedores de insumos para su producción, la demanda intermedia aumenta como proporción del producto total y crece la generación de efectos de retroalimentación entre los sectores. De acuerdo con Aroche Reyes (1993), el índice de complejidad estructural no depende del tamaño de los coeficientes técnicos, sino de la complejidad de la estructura productiva, definida por la presencia de circuitos de retroalimentación entre los sectores, o del nivel de integración entre los sectores. El índice de complejidad estructural se elabora a partir de la matriz de intercambios entre los sectores productivos de una economía. Este enfoque permite comprender mejor el grado de interdependencia entre los sectores de una economía o de su complejidad estructural, una vez que arroja luz sobre el nivel de articulación presente en la estructura productiva.

\section{Inserción en las cadenas globales de valor y evolución de la complejidad estructural del Brasil y México entre 1995 y 2011}

A lo largo de la década de 1990 se fue definiendo el tipo de configuración e inserción comercial de los países latinoamericanos, principalmente el Brasil y México, en un contexto de creciente dispersión geográfica de la producción. Una primera característica es que, en su proceso de liberalización económica, México aplicó medidas más amplias y rápidas que el Brasil. Esto no solo se debe a que comenzaron a implementarse en 1986, cuando México ingresó al Acuerdo General sobre Aranceles Aduaneros y Comercio (GATT), sino también a la rapidez e intensidad de la reducción de los aranceles, así como a las medidas de protección no arancelarias, una tendencia que se reforzó con la firma del Tratado de Libre Comercio de América del Norte (TLCAN) en 1994.

Aunque en momentos diferentes, el período posterior a la apertura comercial y de inserción en las cadenas globales de valor se caracteriza por una fuerte relación positiva entre la tasa de crecimiento del producto interno bruto (PIB) y la tasa de crecimiento de las importaciones en los dos países. En el período de 2004 a 2010, que corresponde al auge de los productos básicos, el Brasil experimentó un crecimiento vertiginoso de las importaciones. En el gráfico 1 se observa una gran concentración de puntos exactamente entre esos dos años. Uno de los factores señalados fue la persistente apreciación del tipo de cambio real a partir de 2003, como parte de la política macroeconómica de control de la inflación y aumento del salario real de los trabajadores.

Es posible apreciar que el proceso de apertura comercial, que comenzó a finales de la década de 1980 y se profundizó a lo largo de la década de 1990, fomentó la dependencia estructural de la economía brasileña de las importaciones. El carácter estructural deriva de que los insumos importados en los ciclos expansivos de la economía brasileña tienden a cerrar cada vez más los circuitos de demanda intermedia de los sectores nacionales. El resultado de esta mayor dependencia sería un mayor debilitamiento de la estructura productiva, en el sentido de que los efectos de encadenamiento entre los sectores tenderían a disminuir. 


\section{Gráfico 1}

Brasil: variación anual del producto interno bruto (PIB) y de las importaciones, 1996-2011

(En porcentajes)

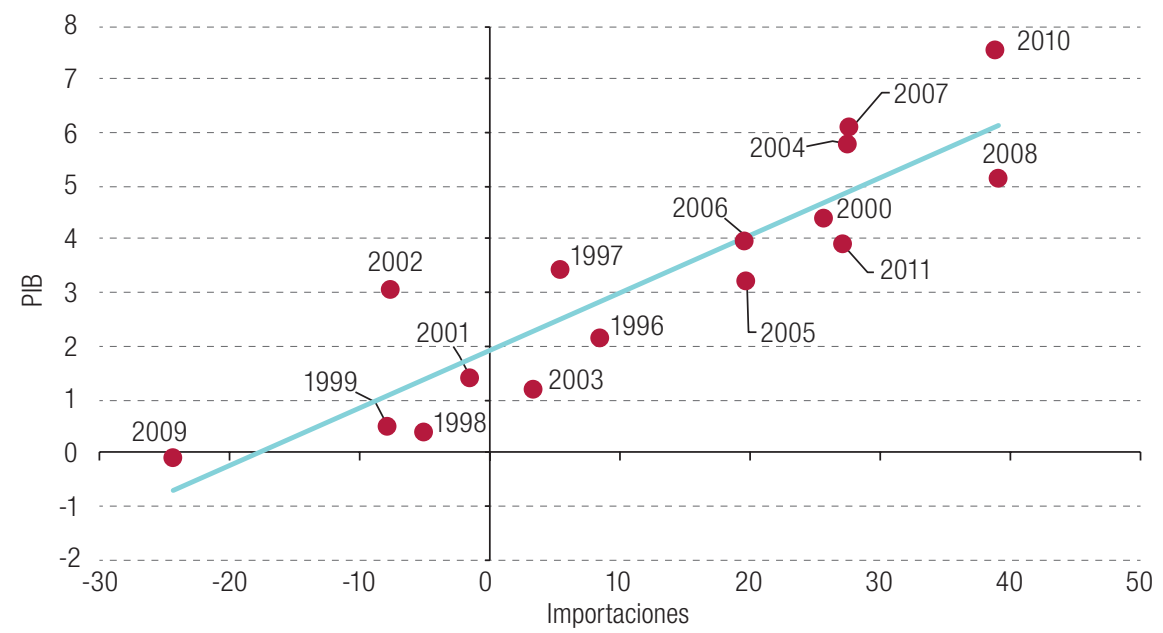

Fuente: Elaboración propia, sobre la base de Comisión Europea, World Input-Output Database, 2013 [en línea] http://www.wiod. org/home, y Comisión Económica para América Latina y el Caribe (CEPAL), CEPALSTAT, 2020 [base de datos en línea] https://estadisticas.cepal.org/cepalstat/portada.html?idioma=spanish.

El caso de México revela un patrón bastante similar al brasileño, con una fuerte relación entre las tasas de crecimiento del PIB y de las importaciones (véase el gráfico 2). Sin embargo, a diferencia del Brasil, los puntos están más dispersos en el tiempo. La firma del TLCAN en 1994 y la apreciación del tipo de cambio real en 1995 (López, 1998) tuvieron el efecto conjunto de profundizar una dependencia de las importaciones establecida históricamente, en particular de aquellas procedentes de los Estados Unidos. Para autores como López (1998) y Ros (2015), el escaso crecimiento de la economía mexicana en el período examinado se relaciona con el aumento del coeficiente de importación. Este aumento habría dado lugar a que los impulsos derivados de la demanda interna se filtraran del mercado interno, disminuyendo el multiplicador del gasto autónomo.

\section{Gráfico 2}

México: variación anual del producto interno bruto (PIB) y de las importaciones, 1996-2011 (En porcentajes)

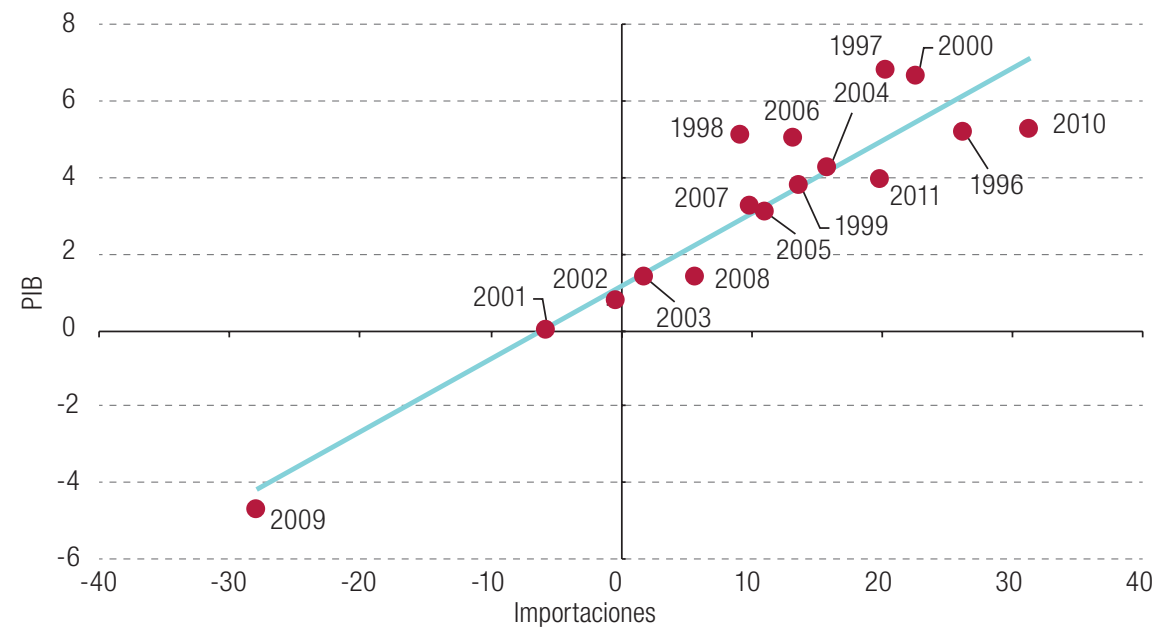

Fuente: Elaboración propia, sobre la base de Comisión Europea, World Input-Output Database, 2013 [en línea] http://www.wiod. org/home, y Comisión Económica para América Latina y el Caribe (CEPAL), CEPALSTAT, 2020 [base de datos en línea] https://estadisticas.cepal.org/cepalstat/portada.html?idioma=spanish. 
De acuerdo con Moreno-Brid y Ros (2010), en lo que respecta al comercio exterior México constituyó uno de los países de mayor expansión de la región y del mundo, en particular en la década de 1990. Este crecimiento se observó en las exportaciones, pero también en el peso de los componentes y los insumos importados, que creció con mayor rapidez que las exportaciones. Como resultado, el país presentó, por una parte, superávits comerciales con los países del TLCAN, pero déficits cada vez mayores con los demás países, principalmente los asiáticos. El efecto final fue la aparición de déficits persistentes en las transacciones corrientes y presiones adicionales sobre la balanza de pagos (Moreno-Brid y Ros, 2010).

El análisis de los patrones de exportación e importación del Brasil revela que, mientras las importaciones presentan una mayor diversificación, las exportaciones se caracterizan por una creciente concentración en un pequeño grupo de sectores. Una forma sintética de analizar la evolución de ambos patrones es mediante el cálculo de la contribución a la variación de las importaciones y exportaciones totales por sector ${ }^{5}$. El cuadro 2 revela que aproximadamente el 45\% de la contribución a la variación de las exportaciones se concentró en apenas tres sectores, a saber: alimentos, bebidas y tabaco (18\%), extracción vegetal (15\%) y agricultura, caza, silvicultura y pesca (12\%). En el caso de las importaciones, se observa una mayor dispersión de las contribuciones sectoriales, que indica que la penetración de las importaciones en la economía brasileña tuvo lugar de forma más generalizada desde el proceso de apertura comercial en 1994 y a lo largo del proceso de integración a las cadenas globales de valor en la década de 2000.

Es interesante observar que, incluso en el sector agropecuario y la construcción (cuyas cadenas productivas están integradas verticalmente), hubo una mayor penetración de las importaciones. Otro hecho que llama la atención es el papel de siete sectores como principales contribuyentes, tanto a la variación de las importaciones como de las exportaciones. Por una parte, estos resultados sugieren una mayor presencia de comercio intrasectorial pero, por otra, muestran la existencia de desequilibrios en las balanzas comerciales de determinados sectores, como equipos de transporte, coque y petróleo refinado y químico y productos químicos.

\section{Cuadro 2}

Brasil: principales sectores que contribuyen a la variación de las importaciones y las exportaciones totales, 1995-2011

(En porcentajes)

\begin{tabular}{lllr}
\hline Importaciones & \multicolumn{3}{l}{ Exportaciones } \\
\hline Equipos de transporte & 9 & Alimentos, bebidas y tabaco & 18 \\
\hline Coque, petróleo refinado y combustible nuclear & 8 & Extracción vegetal & 15 \\
\hline Químicos y productos químicos & 7 & Agricultura, caza, silvicultura y pesca & 12 \\
\hline Extracción vegetal & 6 & Equipos de transporte & 8 \\
\hline Equipos eléctricos y ópticos & 6 & Metales básicos y metales fabricados & 7 \\
\hline Agricultura, caza, silvicultura y pesca & 6 & Químicos y productos químicos & 5 \\
\hline Construcción & 5 & Coque, petróleo refinado y combustible nuclear & 4 \\
\hline Metales básicos y metales fabricados & 5 & Hoteles y restaurantes & 3 \\
\hline Alimentos, bebidas y tabaco & 4 & Celulosa, papel, impresión y publicación & 2 \\
\hline Maquinaria no especificada & 3 & Transporte terrestre & 2 \\
\hline
\end{tabular}

Fuente: Elaboración propia, sobre la base de Comisión Europea, World Input-Output Database, 2013 [en línea] http:// www.wiod.org/home.

En la economía mexicana se observa una mayor concentración de las contribuciones, tanto con respecto a las exportaciones como a las importaciones. Las mayores contribuciones a la variación de las importaciones se registraron en los sectores de equipos eléctricos y ópticos (21\%), equipos

5 De acuerdo con Britto (2002), la contribución sectorial se calcula de la siguiente forma: $\frac{\left(m_{2011}^{i}-m_{1995}^{i}\right)}{\left(m_{2011}^{t}-m_{1995}^{t}\right)} * 100$. 
de transporte (14\%) y construcción (9\%), mientras las mayores contribuciones a la variación de las exportaciones también corresponden a los sectores de equipos de transporte (25\%), equipos eléctricos y ópticos (21\%) y extracción vegetal (18\%) (véase el cuadro 3). Estos resultados muestran que, al contrario del caso brasileño, el patrón de comercio exterior mexicano es sumamente complementario, en el sentido de que depende de las exportaciones y las importaciones de los mismos sectores.

Cuadro 3

México: principales sectores que contribuyen a la variación de las importaciones y las exportaciones totales, 1995-2011

(En porcentajes)

\begin{tabular}{llll}
\hline Importaciones & \multicolumn{3}{l}{ Exportaciones } \\
\hline Equipos eléctricos y ópticos & 21 & Equipos de transporte & 25 \\
\hline Equipos de transporte & 14 & Equipos eléctricos y ópticos & 21 \\
\hline Construcción & 9 & Extracción vegetal & 3 \\
\hline Metales básicos y metales fabricados & 7 & Maquinaria no especificada & 3 \\
\hline Transporte terrestre & 4 & Alimentos, bebidas y tabaco & 3 \\
\hline Electricidad, gas y agua & 4 & Comercio al por mayor & 3 \\
\hline Agricultura, caza, silvicultura y pesca & 3 & Químicos y productos químicos & 2 \\
\hline Extracción vegetal & 3 & Comercio al por menor & 2 \\
\hline Venta, mantenimiento y reparación & 3 & Otras manufacturas & 2 \\
\hline de vehículos automóviles & 3 & Coque, petróleo refinado y combustible nuclear & 2 \\
\hline
\end{tabular}

Fuente: Elaboración propia, sobre la base de Comisión Europea, World Input-Output Database, 2013 [en línea] http:// www.wiod.org/home.

Los resultados acerca de los patrones de comercio exterior del Brasil y México muestran la manera en que los dos países adoptaron diferentes estrategias de inserción externa a lo largo de los años noventa y en la década de 2000. Como señala Katz (2000), esos diferentes patrones de inserción externa surgieron ya en la década de 1980, cuando ambos países abandonaron la industrialización por sustitución de importaciones y adoptaron diferentes estrategias de desarrollo, haciendo hincapié en la apertura comercial por medio de reducciones arancelarias y no arancelarias (Ros, 1994; Kume, 1996).

La reestructuración industrial que siguió a la apertura comercial del Brasil y México entre las décadas de 1980 y 1990 introdujo un fuerte componente estructural en las importaciones, reforzando los patrones de especialización comercial y las estructuras productivas que se constituyeron en el período de industrialización por sustitución de importaciones (Coutinho, 1997; Ros, 2015). De acuerdo con Coutinho (1997), Britto (2002) y Moreno-Brid y Ros (2010), este carácter estructural de las importaciones de insumos intermedios estaría relacionado con el creciente debilitamiento de las estructuras productivas. Según esos autores, el debilitamiento asumió diversas formas, como la reducción del valor agregado de las cadenas industriales, la sustitución de la oferta nacional por proveedores extranjeros y la sustitución de la producción nacional por insumos importados.

En los cuadros 4 y 5 se muestran los diez principales insumos intermedios importados y exportados por el Brasil y México, respectivamente, entre 1994 y $2014^{6}$. Desde el punto de vista de la economía brasileña, se observa un crecimiento de los insumos intermedios que se importan y exportan simultáneamente. En 1994, solo dos insumos intermedios se exportaron e importaron simultáneamente.

\footnotetext{
6 Debido a que los datos de las matrices de la World Input-Output Database (WIOD) están agregados al nivel de 35 sectores, no es posible investigar con mayor detalle la evolución de los insumos intermedios exportados e importados por el Brasil y México. La forma que se encontró para superar esta limitación fue utilizar la Clasificación Uniforme para el Comercio Internacional, Revisión 3 [en línea] https://unstats.un.org/unsd/tradekb/Knowledgebase/50085/Standard-International-Trade-ClassificationRevision-3, específicamente las partes, piezas y componentes incluidos en los capítulos 7 (máquinas y equipos de transporte) y 8 (manufacturas diversas) a 4 y 5 dígitos. Para ver la lista completa de los insumos intermedios con sus respectivos códigos de la Clasificación Uniforme para el Comercio Internacional, Revisión 3, véase Athukorala y Menon (2010).
} 
Corresponden a los códigos 78433 y 78439 de la Clasificación Uniforme para el Comercio Internacional, Revisión 3 y están incluidos en la categoría de partes y accesorios para automóviles. En 2014, siete de los diez principales insumos intermedios se exportaron e importaron simultáneamente, a saber: $71491,78439,7478,79295,78432,78434$ y 78435 . Los datos muestran que en el comercio exterior de insumos intermedios del Brasil tienen gran peso las categorías correspondientes a partes y piezas para automóviles, máquinas y equipos para la generación de energía y máquinas industriales generales. Es interesante notar que la categoría de aparatos y equipos electrónicos presenta una significativa participación en las importaciones, pero no en las exportaciones. Esto revela que el Brasil es un importador para esa categoría de insumos.

\section{Cuadro 4}

Brasil: diez principales insumos intermedios exportados e importados, 1994 y 2014 (Como porcentaje del total de insumos intermedios)

\begin{tabular}{|c|c|c|c|}
\hline $\begin{array}{l}\text { Códigos de la Clasificación Uniforme para } \\
\text { el Comercio Internacional, Revisión } 3\end{array}$ & 1994 & $\begin{array}{l}\text { Códigos de la Clasificación Uniforme para } \\
\text { el Comercio Internacional, Revisión } 3\end{array}$ & 2014 \\
\hline \multicolumn{4}{|l|}{ Exportación } \\
\hline 78439 - Partes y accesorios de automóviles & 16 & $\begin{array}{l}71491 \text { - Máquinas y equipos para la } \\
\text { producción de energía }\end{array}$ & 15 \\
\hline 7611 - Aparatos y equipos de telecomunicaciones & 7 & 78439 - Partes y accesorios de automóviles & 11 \\
\hline $\begin{array}{l}71391 \text { - Máquinas y equipos para la } \\
\text { producción de energía }\end{array}$ & 7 & 7478 - Máquinas industriales generales & 5 \\
\hline $\begin{array}{l}71323 \text { - Máquinas y equipos para la } \\
\text { producción de energía }\end{array}$ & 4 & 79295 - Otros equipos de transporte & 5 \\
\hline 78434 - Partes y accesorios de automóviles & 4 & $\begin{array}{c}71322 \text { - Máquinas y equipos para la } \\
\text { producción de energía }\end{array}$ & 4 \\
\hline 78433 - Partes y accesorios de automóviles & 4 & $\begin{array}{l}71391 \text { - Máquinas y equipos para la } \\
\text { producción de energía }\end{array}$ & 4 \\
\hline 78425 - Partes y accesorios de automóviles & 4 & 78432 - Otros equipos de transporte & 4 \\
\hline 78435 - Partes y accesorios de automóviles & 3 & $\begin{array}{c}7169 \text { - Máquinas y equipos para la } \\
\text { producción de energía }\end{array}$ & 4 \\
\hline 79295 - Otros equipos de transporte & 3 & 78434 - Partes y accesorios de automóviles & 3 \\
\hline $\begin{array}{l}71481 \text { - Máquinas y equipos para la } \\
\text { producción de energía }\end{array}$ & 2 & 78435 - Partes y accesorios de automóviles & 3 \\
\hline \multicolumn{4}{|l|}{ Importación } \\
\hline 78434 - Partes y accesorios de automóviles & 7 & 76493 - Aparatos y equipos de telecomunicaciones & 9 \\
\hline $\begin{array}{l}7128 \text { - Máquinas y equipos para la } \\
\text { producción de energía }\end{array}$ & 7 & 78439 - Partes y accesorios de automóviles & 7 \\
\hline 78439 - Partes y accesorios de automóviles & 6 & 75997 - Máquinas de oficina y automáticas & 6 \\
\hline 77641 - Máquinas, aparatos y equipos eléctricos & 5 & 78434 - Partes y accesorios de automóviles & 6 \\
\hline 76499 - Aparatos y equipos de telecomunicaciones & 4 & 71491 - Aparatos y equipos de telecomunicaciones & 5 \\
\hline 76493 - Aparatos y equipos de telecomunicaciones & 4 & 78432 - Partes y accesorios de automóviles & 4 \\
\hline 75997 - Máquinas de oficina y automáticas & 4 & 79295 - Otros equipos de transporte & 3 \\
\hline 77258 - Máquinas, aparatos y equipos eléctricos & 4 & 78435 - Partes y accesorios de automóviles & 2 \\
\hline 77611 - Máquinas, aparatos y equipos eléctricos & 3 & 7478 - Máquinas industriales generales & 2 \\
\hline 77643 - Máquinas, aparatos y equipos eléctricos & 2 & 7484 - Máquinas industriales generales & 2 \\
\hline
\end{tabular}

Fuente: Elaboración propia, sobre la base de Naciones Unidas, UN Comtrade - Base de Datos Estadísticos sobre el Comercio Internacional, 2017 [en línea] https://comtrade.un.org/.

Nota: Para destacar los grupos de productos de los insumos, las descripciones de las clasificaciones de productos son las del nivel de tres dígitos, más generales que las de cinco dígitos de los principales insumos importados y exportados.

Cuatro de los siete insumos intermedios que se exportaron e importaron simultáneamente en 2014 pertenecen a la categoría de partes y accesorios para automóviles. Estos son: otras piezas y accesorios de carrocerías (78432), cajas de cambios (78434), ejes de transmisión (78435) y otras partes y accesorios (78439). Este patrón de comercio exterior de insumos intermedios revela, por una parte, la existencia de un importante componente de comercio intraindustrial y, por otra, que la inserción del Brasil en las etapas más dinámicas de las cadenas globales de valor tuvo lugar predominantemente por 
medio de la categoría de partes y accesorios para automóviles ${ }^{7}$. Como señalan Souza y Castilho (2016), gran parte de ese comercio tiene lugar dentro de los países pertenecientes al Mercado Común del Sur (MERCOSUR) y con los Estados Unidos.

El análisis del saldo comercial de bienes intermedios del Brasil revela un crecimiento de los déficits comerciales entre 1994 y 2014. Como se puede observar en el gráfico 3, mientras en 1994 el déficit era de aproximadamente 2.500 millones de dólares corrientes, en 2014 ascendió a más de 24.000 millones de dólares corrientes. Estos resultados evidencian la baja competitividad de la producción nacional con respecto a los insumos importados, desde la consolidación del proceso de apertura comercial en 1994 hasta la mayor integración en las cadenas globales de valor durante la primera década del siglo XXI. Así, este patrón de especialización comercial de los bienes intermedios centrado en la categoría de partes y accesorios para automóviles presionó aún más los déficits en la balanza comercial del sector de bienes manufacturados (Marconi, 2015).

\section{Gráfico 3}

Brasil: saldo comercial de bienes intermedios, 1994-2016

(En millones de dólares corrientes)

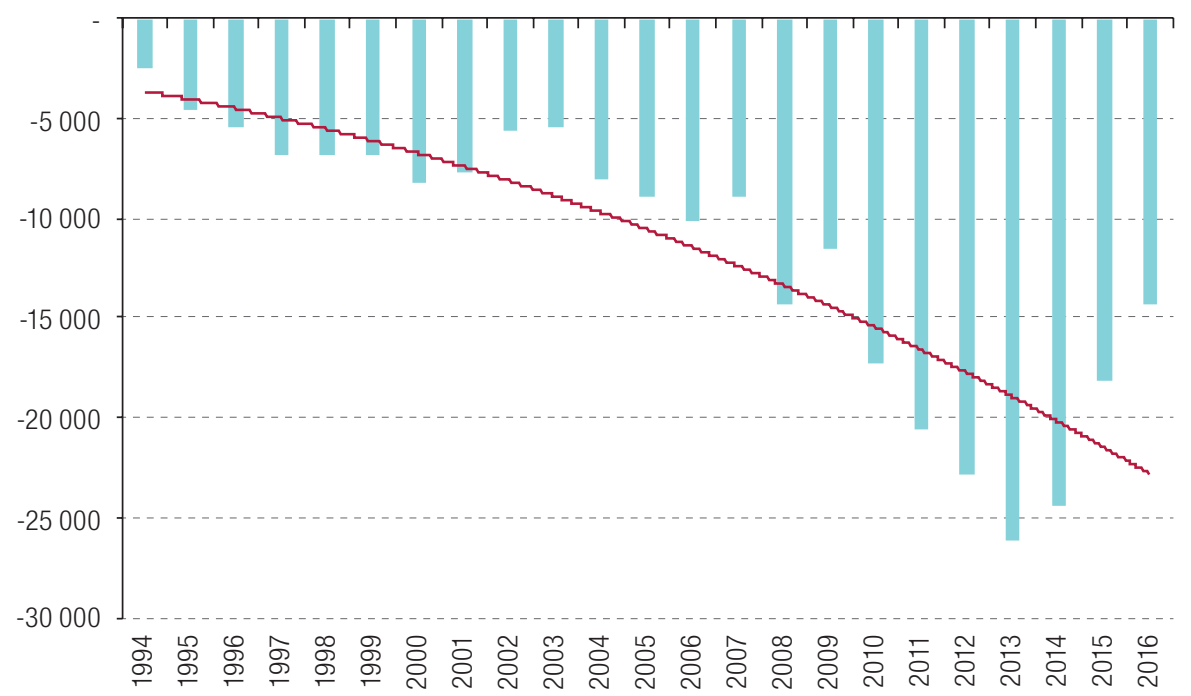

Fuente: Elaboración propia, sobre la base de Naciones Unidas, UN Comtrade - Base de Datos Estadísticos sobre el Comercio Internacional, 2017 [en línea] https://comtrade.un.org/.

En el cuadro 5 se presentan los datos sobre las exportaciones e importaciones de insumos intermedios de la economía mexicana entre 1996 y $2014^{8}$. El flujo total de comercio (exportaciones más importaciones) de bienes intermedios de la economía mexicana es superior al registrado en la economía brasileña, pues en 2014 alcanzó más de 160 millones de dólares en México y poco más de 46 millones de dólares en el Brasil. Esto significa que el flujo comercial de insumos intermedios realizado por la economía mexicana triplica con creces el del Brasil. Cabe recordar que los insumos intermedios son las partes, piezas y accesorios incluidos en los capítulos 7 y 8 de la Clasificación Uniforme para el Comercio Internacional, Revisión 3, teniendo en cuenta que las mayores tasas de crecimiento de insumos intermedios se verificaron en esos artículos (Athukorala y Menon, 2010).

\footnotetext{
7 También se puede incluir la categoría "otras partes de aviones y helicópteros" (79295). La exportación de esos productos es realizada principalmente por la Empresa Brasileira de Aeronáutica, S.A. (EMBRAER), que participa activamente en las cadenas globales de valor.

8 El análisis del comercio exterior de bienes intermedios de la economía mexicana se realizó a partir de 1996 porque 1994 y 1995 son años de crisis en la balanza de pagos de la economía, lo que distorsionaría el análisis del comercio exterior. Esa crisis se conoció como "efecto tequila" (Ibarra y Moreno-Brid, 2001).
} 
En el cuadro 5 se revela además que tanto las importaciones como las exportaciones de insumos intermedios realizadas por México se concentran en un menor número de productos con respecto al Brasil. En el caso de las exportaciones, el mayor peso corresponde a los aparatos y equipos de telecomunicaciones (7611), con una participación en las exportaciones totales de insumos intermedios del $21 \%$. La participación de las exportaciones de máquinas y equipos para la producción de energía se redujo un 10\% entre 1996 y 2014. El mayor aumento se registró en la categoría de partes y piezas de automóviles, cuya participación en 1996 era del 5\% y se basaba en las exportaciones de otras partes y accesorios (78439). En 2014, las exportaciones de partes y piezas para automóviles representaron el $15 \%$, dados los incrementos en las cuotas de exportación de otras partes y piezas de carrocerías (78432), frenos y sus partes (78433), cajas de cambios (78434) y ejes de transmisión (78435). El segmento de otras partes y accesorios de vehículos alcanzó una participación del 12\% en 2013, lo que indica un pronunciado aumento en sus exportaciones para 2014. Así, a diferencia del Brasil, que presentó una pérdida de participación en el segmento de piezas y accesorios para vehículos, el comercio exterior de insumos intermedios de México comenzó a depender cada vez más de la dinámica de esos cinco productos.

\section{Cuadro 5}

México: diez principales insumos intermedios exportados e importados, 1996 y 2014 (Como porcentaje del total de insumos intermedios)

\begin{tabular}{|c|c|c|c|}
\hline $\begin{array}{l}\text { Códigos de la Clasificación Uniforme para } \\
\text { el Comercio Internacional, Revisión } 3\end{array}$ & 1996 & $\begin{array}{l}\text { Códigos de la Clasificación Uniforme para } \\
\text { el Comercio Internacional, Revisión } 3\end{array}$ & 2014 \\
\hline \multicolumn{4}{|l|}{ Exportación } \\
\hline 7611 - Aparatos y equipos de telecomunicaciones & 21 & 7611 - Aparatos y equipos de telecomunicaciones & 21 \\
\hline $\begin{array}{l}71322 \text { - Máquinas y equipos para la } \\
\text { producción de energía }\end{array}$ & 14 & 77313 - Máquinas, aparatos y equipos eléctricos & 9 \\
\hline 76493 - Aparatos y equipos de telecomunicaciones & 9 & 82119 - Muebles y sus partes & 7 \\
\hline 77641 - Máquinas, aparatos y equipos eléctricos & 6 & 78432 - Partes y accesorios de automóviles & 6 \\
\hline 78439 - Partes y accesorios de automóviles & 5 & 77261 - Máquinas, aparatos y equipos eléctricos & 5 \\
\hline 77259 - Máquinas, aparatos y equipos eléctricos & 4 & $\begin{array}{l}71322 \text { - Máquinas y equipos para la } \\
\text { producción de energía }\end{array}$ & 4 \\
\hline 77255 - Máquinas, aparatos y equipos eléctricos & 3 & 78435 - Partes y accesorios de automóviles & 4 \\
\hline 74159 - Máquinas industriales generales & 3 & $\begin{array}{l}71391 \text { - Máquinas y equipos para la } \\
\text { producción de energía }\end{array}$ & 4 \\
\hline 77812 - Máquinas, aparatos y equipos eléctricos & 2 & 78434 - Partes y accesorios de automóviles & 3 \\
\hline $\begin{array}{l}71392 \text { - Máquinas y equipos para la } \\
\text { producción de energía }\end{array}$ & 2 & 78433 - Partes y accesorios de automóviles & 2 \\
\hline \multicolumn{4}{|l|}{ Importación } \\
\hline 78432 - Partes y accesorios de automóviles & 8 & 78439 - Partes y accesorios de automóviles & 11 \\
\hline 77611 - Máquinas, aparatos y equipos eléctricos & 8 & 75997 - Máquinas de oficina y automáticas & 7 \\
\hline 77645 - Máquinas, aparatos y equipos eléctricos & 7 & 78432 - Partes y accesorios de automóviles & 6 \\
\hline 77259 - Máquinas, aparatos y equipos eléctricos & 5 & $\begin{array}{l}71323 \text { - Máquinas y equipos para la } \\
\text { producción de energía }\end{array}$ & 5 \\
\hline 7722 - Máquinas, aparatos y equipos eléctricos & 5 & 78434 - Partes y accesorios de automóviles & 5 \\
\hline 77643 - Máquinas, aparatos y equipos eléctricos & 4 & 77282 - Máquinas, aparatos y equipos eléctricos & 4 \\
\hline $\begin{array}{l}71391 \text { - Máquinas y equipos para la } \\
\text { producción de energía }\end{array}$ & 4 & 77259 - Máquinas, aparatos y equipos eléctricos & 4 \\
\hline 76493 - Aparatos y equipos de telecomunicaciones & 4 & 7611 - Aparatos y equipos de telecomunicaciones & 3 \\
\hline 75997 - Máquinas de oficina y automáticas & 3 & $\begin{array}{l}71391 \text { - Máquinas y equipos para la } \\
\text { producción de energía }\end{array}$ & 3 \\
\hline 78435 - Partes y accesorios de automóviles & 3 & 78435 - Partes y accesorios de automóviles & 3 \\
\hline
\end{tabular}

Fuente: Elaboración propia, sobre la base de Naciones Unidas, UN Comtrade - Base de Datos Estadísticos sobre el Comercio Internacional, 2017 [en línea] https://comtrade.un.org/.

Nota: Para destacar los grupos de productos de los insumos, las descripciones de las clasificaciones de productos son las del nivel de tres dígitos, más generales que las de cinco dígitos de los principales insumos importados y exportados. 
El brusco proceso de desregulación y la acelerada eliminación de las barreras arancelarias y no arancelarias al comercio que caracterizaron la estrategia de desarrollo económico adoptada por México en la década de 1980 provocaron un cambio abrupto en su patrón de comercio. El nuevo patrón de comercio exterior, basado en las exportaciones e importaciones de insumos de partes, piezas y componentes de los sectores de equipos de transporte y equipos eléctricos y ópticos, aceleró el ritmo de los déficits comerciales del país a lo largo de la década de 1990. Otra característica preocupante de ese patrón de comercio exterior es el aumento del contenido importado de insumos intermedios presente en las exportaciones mexicanas (Fujii y Cervantes, 2013), que tiende a presionar aún más la balanza de pagos de la economía.

En el gráfico 4 se muestra que, después de la firma del TLCAN en 1994, el saldo comercial de bienes intermedios de la economía mexicana tendió a deteriorarse. De acuerdo con Moreno-Brid y Ros (2010), la participación de México en el TLCAN tuvo resultados aparentemente contradictorios en la balanza comercial del país: por una parte, aumentó el superávit comercial con sus socios comerciales del TLCAN mientras, por otra, se deterioró el saldo comercial con los países asiáticos, en particular China. El resultado global y sectorial para los bienes intermedios fue la aparición de déficits comerciales. A partir de mediados de la década de 2000, esos déficits comerciales en bienes intermedios se invirtieron parcialmente en función del aumento de los superávits comerciales con los Estados Unidos, que compensaron con creces el aumento de los déficits comerciales con China.

\section{Gráfico 4}

México: saldo comercial de bienes intermedios, 1994-2016

(En millones de dólares corrientes)

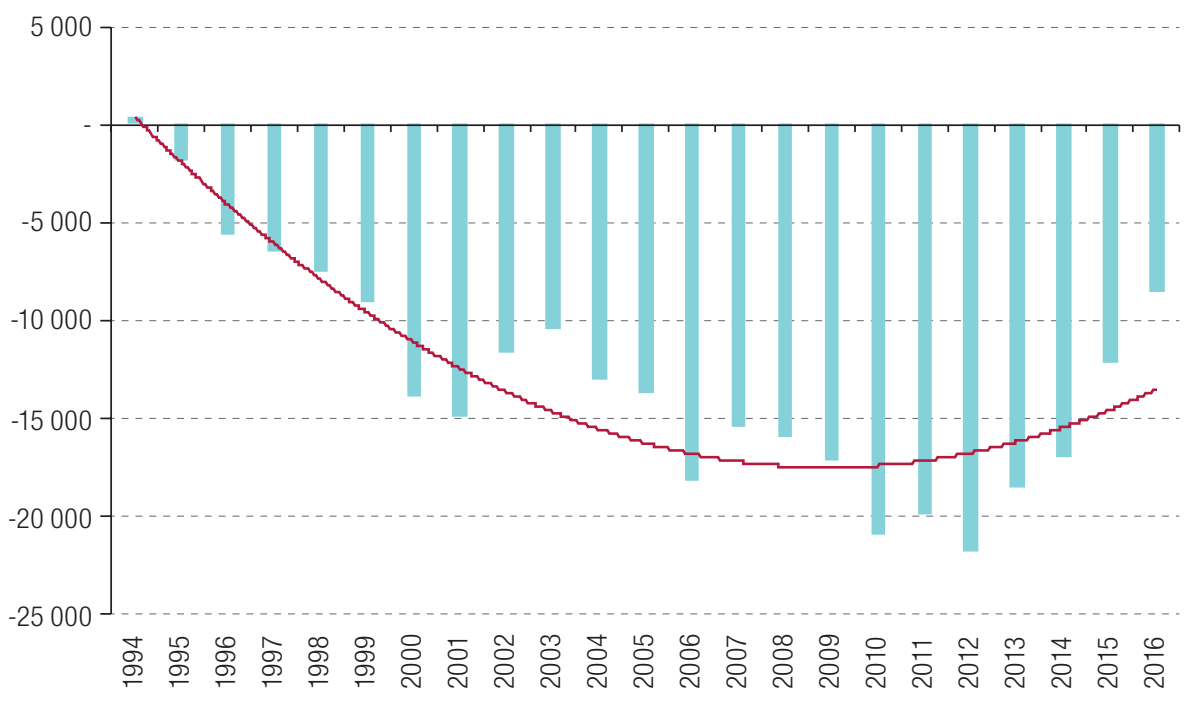

Fuente: Elaboración propia, sobre la base de Naciones Unidas, UN Comtrade - Base de Datos Estadísticos sobre el Comercio Internacional, 2017 [en línea] https://comtrade.un.org/.

Es a partir de estos diferentes patrones de comercio exterior que el Brasil y México se insertan con niveles muy distintos de participación en las cadenas globales de valor. Según Medeiros y Trebat (2018), estos diferentes patrones de inserción en las cadenas globales de valor dentro del conjunto de países periféricos muestran el carácter asimétrico de esa inserción. La asimetría está relacionada con la creciente concentración y centralización del poder de mando sobre el valor creado en las cadenas globales de valor, de manera que países como el Brasil y México participan en diferentes etapas de los procesos productivos. Esta asimetría es aún más relevante cuando se tiene en cuenta la capacidad de los países periféricos para apropiarse del valor creado dentro de las cadenas globales de valor. 
El carácter jerárquico de la nueva división internacional del trabajo promueve una competencia feroz en las etapas de producción con menor capacidad para generar valor agregado, como el procesamiento de materias primas (Brasil), que presentan salarios más bajos y menores márgenes de beneficio para los trabajadores y las empresas, respectivamente. En la cima de la jerarquía prevalece otro patrón de competencia, centrado en la capacidad de dirigir los flujos de bienes y servicios e innovación, caracterizado por salarios más altos y mayores márgenes de beneficio para los trabajadores y las empresas (Medeiros y Trebat, 2018).

Como se puede observar en el cuadro 6, en el período comprendido entre 1995 y 2011 hubo un aumento generalizado del contenido extranjero presente en las exportaciones brasileñas y mexicanas. En el caso del Brasil, el valor agregado contenido en las exportaciones aumentó 3 puntos porcentuales, al pasar del 7,8\% al 10,8\%. De acuerdo con los estudios de Hermida (2016), Côrrea (2016) y Castilho, Torracca y Freitas (2019), esa proporción brasileña es relativamente pequeña con respecto a la de los países desarrollados y periféricos. Aunque ese porcentaje todavía evidencia una baja participación del país en las cadenas globales de valor, se constata un importante crecimiento en la participación de un conjunto de sectores. Esos aumentos se concentraron en los sectores de fabricación de vehículos automóviles $(7,2 \%)$, caucho y plásticos $(6,7 \%)$, máquinas y equipos eléctricos (6,6\%), otros equipos de transporte (6,5\%) y equipos eléctricos y ópticos (6,5\%). Como resultado, la participación del valor agregado importado en las exportaciones de manufacturas nacionales aumentó un 4,2\% entre 1995 y 2011.

La participación de la economía mexicana en las cadenas globales de valor fue casi tres veces superior con respecto a la de la economía brasileña, al pasar del 27,3\% al 31,7\% entre 1995 y 2011. Desde el punto de vista de las manufacturas, esa diferencia es aún mayor, dado que, en 2011, el valor agregado extranjero contenido en las exportaciones de manufacturas fue del 43,5\% en México y del $14,3 \%$ en el Brasil. Dentro del sector manufacturero mexicano, los mayores incrementos se registraron en los sectores de coque, productos petrolíferos refinados y de combustible nuclear (19,3\%), caucho y plásticos (14,4\%) y productos químicos (11,5\%).

Los patrones divergentes de especialización comercial y participación en las cadenas de valor tendieron a reforzar la participación del Brasil en las fases iniciales, es decir, en las primeras etapas de los procesos de producción mediante la exportación de materias primas. La participación de México, por otra parte, es más intensa y se localiza en las fases ulteriores de las cadenas de valor, cuando el país procesa insumos intermedios para su posterior exportación. Pese a los diferentes motivos que explican la escasa capacidad de integración del Brasil en esas redes -como, por ejemplo, la "excesiva" verticalización industrial heredada del período de sustitución de importaciones (Canuto, Fleischhaker y Schellekens, 2015)- es indudable que el reciente aumento en la utilización de insumos intermedios importados provocó cambios en la articulación entre los sectores.

En el caso de México, el alto nivel de integración en las cadenas globales de valor no aseguró una fuerte conexión entre el sector manufacturero exportador y la estructura productiva interna. De acuerdo con Ruiz-Nápoles (2004) y Fujii y Cervantes (2012 y 2017), la integración en el TLCAN y la participación más activa de México en las cadenas de valor no lograron, sin embargo, provocar un proceso de reforma estructural dinámica, en el sentido de generación de ingresos y empleos de mayor calificación ${ }^{9}$. El alto contenido importado en las exportaciones de manufacturas mexicanas -y la consiguiente desconexión entre el sector manufacturero exportador y el resto de la economía- se señala como una de las razones de las bajas tasas de crecimiento registradas en el país desde su integración en el TLCAN (MorenoBrid y Ros, 2010). Esa desconexión redujo el efecto multiplicador de las exportaciones en la dinámica de la economía (Ruiz-Nápoles, 2004). Los profundos cambios observados en las exportaciones mexicanas - de un patrón concentrado en las exportaciones de petróleo en la década de 1980 a un

9 Conforme Katz (2000). 
patrón concentrado en productos de mayor intensidad tecnológica- no lograron provocar cambios estructurales en el sentido mencionado anteriormente. De hecho, ese patrón exportador-importador aumentó la rigidez de las exportaciones y la dependencia estructural de los insumos importados.

\section{Cuadro 6}

Brasil y México: valor agregado extranjero contenido en las exportaciones, 1995 y 2011 (Como porcentaje del total exportado)

\begin{tabular}{|c|c|c|c|c|c|c|}
\hline \multirow{2}{*}{ Sectores } & \multicolumn{3}{|c|}{ Brasil } & \multicolumn{3}{|c|}{ México } \\
\hline & 1995 & 2011 & $(\%)$ & 1995 & 2011 & $(\%)$ \\
\hline Total & 7,8 & 10,8 & 3,0 & 27,3 & 31,7 & 4,4 \\
\hline Agricultura, caza, silvicultura y pesca & 4,9 & 9,5 & 4,6 & 5,3 & 10,7 & 5,4 \\
\hline Industrias extractivas y minería & 10,1 & 9,9 & $-0,2$ & 3,3 & 4,3 & 1,0 \\
\hline Total de manufacturas & 10,1 & 14,3 & 4,2 & 38,6 & 43,5 & 4,9 \\
\hline Alimentos, bebidas, tabaco & 7,4 & 9,8 & 2,4 & 15,0 & 16,8 & 1,8 \\
\hline Textiles y productos textiles & 6,0 & 8,9 & 2,9 & 31,6 & 37,5 & 5,9 \\
\hline Madera y corcho y sus manufacturas & 5,2 & 9,2 & 4,0 & 10,1 & 18,2 & 8,0 \\
\hline Pasta de papel y cartón y sus artículos; edición e impresión & 7,8 & 9,6 & 1,8 & 21,9 & 31,6 & 9,7 \\
\hline Coque, productos petrolíferos refinados y de combustible nuclear & 18,2 & 21,4 & 3,2 & 6,2 & 25,5 & 19,3 \\
\hline Caucho y plásticos & 10,7 & 17,4 & 6,7 & 25,6 & 40,0 & 14,4 \\
\hline Otros productos minerales no metálicos & 9,3 & 12,3 & 3,0 & 13,6 & 18,6 & 5,0 \\
\hline Metales básicos & 13,6 & 15,8 & 2,2 & 20,6 & 16,6 & $-4,0$ \\
\hline Fabricación de productos metálicos & 9,7 & 13,1 & 3,4 & 41,0 & 45,8 & 4,8 \\
\hline Otras manufacturas; reciclables & 5,2 & 8,5 & 3,3 & 38,9 & 48,6 & 9,6 \\
\hline Máquinas y equipos & 10,6 & 16,2 & 5,6 & 32,5 & 37,2 & 4,8 \\
\hline Productos químicos & 11,4 & 15,8 & 4,5 & 14,8 & 26,3 & 11,5 \\
\hline Máquinas y aparatos eléctricos & 13,3 & 19,9 & 6,6 & 54,8 & 58,3 & 3,5 \\
\hline Fabricación de vehículos automóviles, remolques y semirremolques & 12,7 & 19,9 & 7,2 & 40,8 & 49,6 & 8,8 \\
\hline Otros equipos de transporte & 12,0 & 18,5 & 6,5 & 24,5 & 33,2 & 8,7 \\
\hline Equipos eléctricos y ópticos & 17,6 & 24,1 & 6,5 & 62,0 & 64,1 & 2,1 \\
\hline Electricidad, gas y agua & 2,1 & 5,9 & 3,8 & 7,6 & 15,3 & 7,8 \\
\hline Construcción & 6,3 & 8,9 & 2,6 & 11,3 & 11,3 & 0,0 \\
\hline Comercio al por mayor y al por menor, reparaciones & 1,0 & 3,2 & 2,3 & 4,9 & 4,3 & $-0,6$ \\
\hline Hoteles y restaurantes & 4,1 & 6,2 & 2,2 & 3,5 & 4,0 & 0,5 \\
\hline Transporte y almacenamiento & 6,0 & 10,0 & 4,1 & 5,6 & 8,6 & 3,0 \\
\hline $\begin{array}{l}\text { Servicios postales y de telecomunicaciones } \\
\text { Intermediación financiera }\end{array}$ & $\begin{array}{l}5,2 \\
1,9\end{array}$ & $\begin{array}{l}5,9 \\
3,3\end{array}$ & $\begin{array}{l}0,8 \\
1,4\end{array}$ & $\begin{array}{l}7,0 \\
2,2\end{array}$ & $\begin{array}{r}12,2 \\
3,5 \\
\end{array}$ & $\begin{array}{l}5,2 \\
1,3\end{array}$ \\
\hline Actividades inmobiliarias & 0,5 & 0,7 & 0,3 & 1,4 & 1,0 & $-0,4$ \\
\hline Alquiler de máquinas y equipos & 6,8 & 7,5 & 0,8 & 4,7 & 5,6 & 0,9 \\
\hline Computación y actividades relacionadas & 2,9 & 7,0 & 4,0 & 3,4 & 2,8 & $-0,6$ \\
\hline Investigación y desarrollo y otras actividades de negocios & 3,7 & 4,8 & 1,1 & 5,0 & 3,2 & $-1,9$ \\
\hline Administración pública y defensa; seguridad social obligatoria & 3,0 & 4,2 & 1,2 & 1,5 & 1,4 & $-0,1$ \\
\hline Educación & 2,6 & 3,3 & 0,7 & 4,8 & 4,7 & $-0,1$ \\
\hline Salud y acción social & 5,1 & 6,8 & 1,7 & 5,9 & 5,4 & $-0,5$ \\
\hline Otras actividades de servicios colectivos, sociales y personales & 5,6 & 6,5 & 0,9 & 35,0 & 37,0 & 2,1 \\
\hline
\end{tabular}

Fuente: Elaboración propia, sobre la base de Comisión Europea, World Input-Output Database, 2013 [en línea] http://www. wiod.org/home.

Las estructuras productivas de los dos países respondieron de distintas formas a las transformaciones del comercio exterior. No obstante, el resultado común a ambos países fue lo que convencionalmente se denominó pérdida de densidad o de complejidad en el grado de articulación entre los sectores 
(Coutinho, 1997; Britto, 2002; Marconi, 2015). Los estudios indican que, en general, esa pérdida de complejidad se relaciona con el menor peso de las manufacturas en el valor agregado (Marconi, 2015), la reducción del valor de los índices de encadenamiento hacia atrás y hacia adelante o la pérdida de eslabones en varias partes de las cadenas productivas (Coutinho, 1997; Kupfer, 2005). El análisis de la complejidad a partir de los determinantes de las matrices de insumo-producto permite una lectura complementaria de los indicadores previamente analizados.

Como se puede observar en el gráfico 5, el índice de complejidad estructural disminuyó en los dos países a lo largo del período examinado y la estructura productiva brasileña resultó más compleja que la mexicana. El índice de complejidad estructural se redujo de 21,5 a 10,7 (variación negativa de 10,8) en el Brasil y de 8,3 a 4,4 (variación negativa de 3,9) en México. Es interesante señalar que, si bien las estrategias de inserción internacional de las dos economías difieren en términos de intensidad y ambos países se encuentran en diferentes etapas de las cadenas globales de valor, tanto Brasil como México registraron una pérdida de complejidad en sus estructuras productivas.

\section{Gráfico 5}

Brasil y México: índice de complejidad estructural, 1995-2011

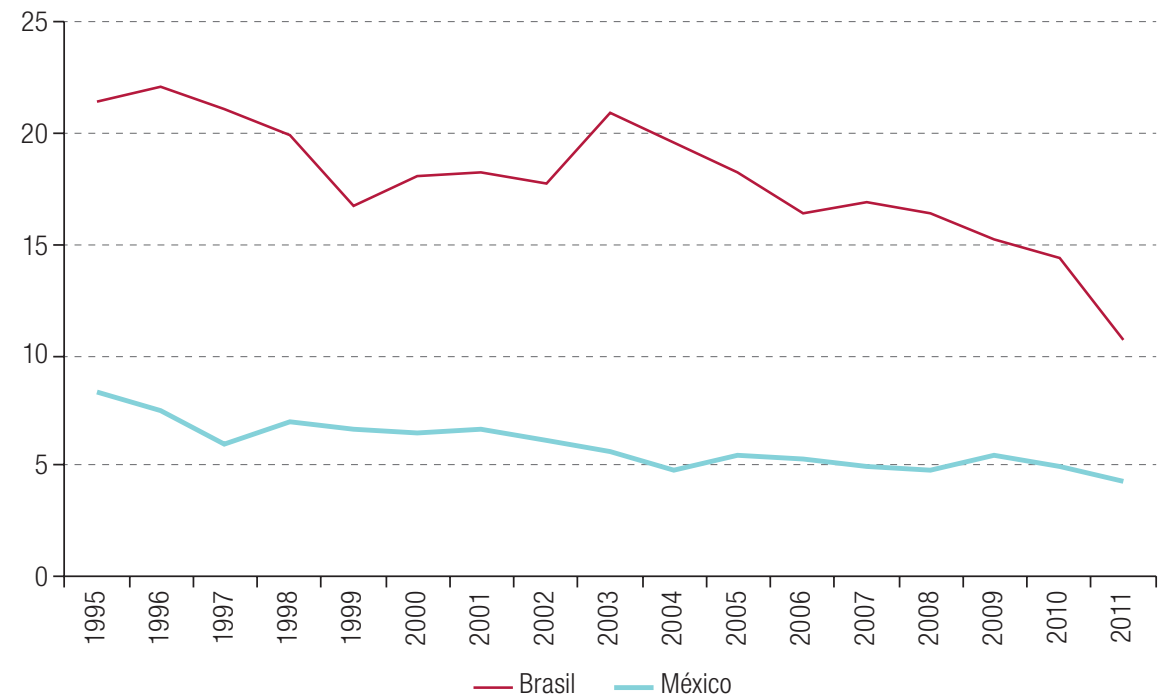

Fuente: Elaboración propia, sobre la base de Comisión Europea, World Input-Output Database, 2013 [en línea] http://www. wiod.org/home.

Entre los diferentes motivos señalados para esa pérdida de complejidad se encuentra la mayor dependencia de la producción nacional de los insumos intermedios importados, que parece haber sido el resultado de la combinación de la mayor apertura comercial y los comportamientos microeconómicos de las empresas nacionales y transnacionales instaladas en los países. La mayor integración supuso un aumento generalizado del contenido importado presente en la articulación entre los sectores. Aunque en diferentes grados, la inserción del Brasil y México en las redes mundiales de producción y de valor a lo largo de la década de 2000 parece haber reforzado los patrones de especialización comercial heredados de la década anterior. Esto se debe a que el Brasil y México comenzaron a depender cada vez más de la importación de partes, piezas y accesorios que, a su vez, tendió a aumentar la rigidez de sus patrones de exportación. El Brasil y México necesitaban mayores tasas de crecimiento de los sectores tradicionalmente exportadores, a fin de generar superávits comerciales y, así, contener los déficits en las transacciones corrientes.

Los resultados muestran que las diferencias en los modelos de inserción externa de las dos economías dieron lugar en ambos casos a una mayor dependencia de los insumos importados. A lo 
largo de la década de 2000, el patrón comercial mexicano fue el resultado de la profundización de las políticas económicas de incentivos a las maquiladoras (Moreno-Brid y Ros, 2010), con un fuerte contenido de insumos importados de las diversas filiales de las empresas transnacionales, mientras el patrón comercial brasileño siguió una trayectoria de mayor reprimarización, con un aumento del contenido importado de la producción. Esto supuso estructuras de comercio exterior progresivamente diferentes desde el punto de vista de las exportaciones, pero no desde el punto de vista de las importaciones, como se mostró al comienzo de esta sección ${ }^{10}$. Por una parte, las exportaciones mexicanas se concentraron en bienes manufacturados con un alto nivel de complejidad económica y contenido tecnológico, mientras, por otra parte, el peso de las exportaciones de productos básicos agrícolas e industriales en las exportaciones brasileñas creció de forma pronunciada con el ciclo de auge de los productos básicos, una de cuyas características es el bajo nivel de complejidad económica o tecnológica.

Como se mencionó al comienzo de esta sección, el análisis desde la perspectiva de las importaciones evidenció un creciente déficit comercial de insumos intermedios para ambas economías. Ese persistente déficit indica que los circuitos de demanda de bienes intermedios, que antes eran atendidos por productores nacionales, fueron gradualmente sustituidos por proveedores extranjeros ${ }^{11}$. De acuerdo con Medeiros, Freitas y Passoni (2019), Marcato y Ultremare (2018) y Fujii y Cervantes (2013), el aumento de la penetración de las importaciones provocó movimientos de vaciado de la demanda de insumos intermedios hacia el exterior, generando problemas de pérdida de densidad de la estructura productiva.

Estos resultados son importantes en la medida en que muestran la manera en que el modelo mexicano de maquilas dio lugar a un aumento de la complejidad económica de sus exportaciones pero a una disminución de la complejidad de su estructura productiva; mientras el modelo brasileño registró una disminución de los dos indicadores, en su complejidad económica y estructural. Así, aunque los países difieren en cuanto a los modelos de inserción externa adoptados, esas diferencias tuvieron un resultado común: la pérdida de complejidad de las estructuras productivas. Llama la atención que esa reducción de la complejidad estructural de las dos economías se produjo simultáneamente con una mayor dependencia de los insumos importados, lo que arroja luz sobre el papel desempeñado en esas economías por las importaciones de insumos, que pueden estar sustituyendo los circuitos de demanda intermedia antes atendidos por los productores nacionales (Costa, Castilho y Puchet, 2018).

\section{Conclusiones}

En este artículo se analizaron los efectos de los patrones de especialización comercial, en un ambiente de fragmentación productiva, en las estructuras productivas del Brasil y México entre 1995 y 2011 . El estudio procura contribuir no solo a la comprensión de los procesos de cambio estructural en el Brasil y México, sino también, desde el punto de vista analítico y metodológico, al análisis de la complejidad de las economías apoyándose en la utilización del índice de complejidad estructural. Este índice permite comprender la manera en que los sectores se articulan y determinar los efectos de las exportaciones e

\footnotetext{
${ }^{10}$ La divergencia entre las estructuras de exportaciones de México y el Brasil se observa en la evolución de los índices de complejidad económica estimados en el Atlas of Economic Complexity, coordinado por Hausmann [en línea] http://atlas.cid. harvard.edu/rankings/2010?country=chi que, como se comentó anteriormente, se basa en la composición de las exportaciones de los países. En el caso de México, el índice de complejidad económica aumentó y su posición en la clasificación mejoró. En el caso del Brasil ocurrió lo contrario, pues ambos se deterioraron entre 1995 y 2010.

${ }^{11}$ Costa (2017) calcula el índice de complejidad estructural para ambas economías a partir de la diferencia entre las matrices nacional y total (demanda intermedia nacional más demanda intermedia importada). Este cálculo permitió verificar que una parte cada vez mayor de los circuitos de demanda intermedia se cerraba por causa de los proveedores extranjeros mediante importaciones.
} 
importaciones en el grado y el patrón de interdependencia entre ellos, es decir, una mejor comprensión de las relaciones entre cambio estructural y comercio exterior.

La realización del estudio comparativo de estas dos economías se justifica por diversas razones. Las principales son la similitud del tamaño y la diversificación de los sectores industriales de los dos países y el hecho de que constituyan las dos mayores economías de América Latina, que les confiere un importante papel en la dinámica de las demás economías de la región. Por una parte, el Brasil presentó una tendencia a la especialización en las exportaciones de productos basados en recursos naturales, mientras por el lado de las importaciones comenzó a depender cada vez más de los insumos intermedios extranjeros, principalmente máquinas y equipos de transporte. Por otra parte, México concentró sus exportaciones en las maquilas manufactureras de exportación, en particular en los sectores de máquinas y materiales de transporte y equipos eléctricos. Las importaciones mexicanas se concentraron en insumos intermedios para los sectores de máquinas y equipos de transporte y equipos eléctricos.

La inserción de los dos países en las cadenas globales de valor tendió a profundizar los patrones de comercio establecidos durante la década de 1990. El Brasil tendió a reforzar su inserción en las fases iniciales de las cadenas de valor, es decir, en las primeras etapas de los procesos de producción con la exportación de materias primas. México presentó una participación más intensa en dichas cadenas, con una localización en las fases ulteriores, cuando el país procesa insumos intermedios importados para su posterior exportación. Si bien la participación mexicana en las cadenas globales de valor es más intensa, no se caracteriza por la existencia de una fuerte conexión entre el sector manufacturero exportador y la estructura productiva interna, capaz de generar procesos de reforma estructural dinámica, lo que explica, al menos en parte, el bajo nivel de complejidad de la economía mexicana. En el período analizado, ambas economías mostraron una pérdida de complejidad, debido al aumento del contenido importado de bienes intermedios. Para México, la integración en el TLCAN y la mayor inserción en las cadenas de valor fueron dos fenómenos estrechamente relacionados, con efectos limitados en los ingresos, el empleo y la generación de valor agregado nacional con respecto a lo que se esperaba a comienzos de la década de 1990.

Desde el punto de vista de la estructura de las importaciones, la coincidencia entre los principales sectores importadores en 1995 y 2011 denota cierta rigidez en el patrón productivo de ambas economías. En este sentido, los acuerdos regionales (el MERCOSUR y el TLCAN) y la inserción en las cadenas globales de valor parecen profundizar las características heredadas del período de industrialización por sustitución de importaciones. Una de esas características es la incapacidad de la oferta interna de bienes intermedios para satisfacer la demanda en momentos de fuerte crecimiento económico, que se traduce en una mayor dependencia de los insumos intermedios importados. Esa mayor presencia de insumos importados planteó interrogantes sobre el acontecimiento de un proceso de desindustrialización o pérdida de densidad de la estructura productiva brasileña y de una menor capacidad de desbordamiento de las maquilas mexicanas a la economía nacional. La persistente disminución de los índices de complejidad estructural de ambas economías indica que esa mayor presencia de insumos importados, que sustituyeron a los insumos nacionales en los circuitos de demanda intermedia, parece haber influido negativamente en la complejidad estructural de los dos países.

\section{Bibliografía}

Adami, C. (2002), "What is complexity?", BioEssays, vol. 24, № 12, diciembre.

Amaral, J., J. Dias y J. Lopes (2007), "Complexity as interdependence in input-output systems", Environment and Planning A: Economy and Space, vol. 39, Nㅜ 7.

Aroche Reyes, F. (1993), "Economic structures in Brazil, Mexico and South Korea: an input-output application", tesis de doctorado, Londres, Queen Mary University of London. 
Arthur, W. (1999), "Complexity and the economy", Science, vol. 284, № 5411, Washington, D.C., Asociación Estadounidense para el Progreso de la Ciencia (AAAS).

Athukorala, P. y J. Menon (2010), "Global production sharing, trade patterns, and determinants of trade flows in East Asia", Working Papers Series on Regional Economic Integration, № 41, Mandaluyong, Banco Asiático de Desarrollo (BAsD), enero.

Baldwin, R. (2011), "Trade and industrialisation after globalisation's 2nd unbundling: how building and joining a supply chain are different and why it matters", NBER Working Paper, № 17716, Cambridge, Oficina Nacional de Investigaciones Económicas (NBER), diciembre.

Basu, R. y T. Johnson (1996), "The development of a measure of intersectoral connectedness by using structural path analysis", Environment and Planning A: Economy and Space, vol. 28, № 4.

Boddin, D. (2016), "The role of newly industrialized economies in global value chains", IMF Working Paper, № 16/207, Washington, D.C., Fondo Monetario Internacional (FMI), octubre.

Bott, R. y J. Mayberry (1954), "Matrices and trees", Economic Activity Analysis, O. Morgenstern (ed.), Nueva York, John Wiley \& Sons.

Britto, G. (2002), "Abertura comercial e reestruturação industrial no Brasil: um estudo dos coeficientes de comércio", tesis de maestría en ciencias económicas, Campinas, Universidad Estadual de Campinas.

Canuto, O., C. Fleischhaker y P. Schellekens (2015), "The curious case of Brazil's closedness to trade", Policy Research Working Paper, № 7228, Washington, D.C., Banco Mundial, abril.

Castilho, M., J. Torracca y F. Freitas (2019), "The competitiveness of Brazilian manufacturing in both domestic and international markets", International Integration of the Brazilian Economy, E. Grivoyannis (ed.), Nueva York, Palgrave Macmillan.

Chenery, H. (1980), "Interactions between industrialization and exports", World Bank Reprint Series, № 150, Washington, D.C., Banco Mundial.

Chenery, H. y T. Watanabe (1958), "International comparisons of the structure of production", Econometrica: Journal of the Econometric Society, vol. 26, № 4, octubre.

Côrrea, L. (2016), "Trajetórias dos países em desenvolvimento nas cadeias globais de valor: upgrading, estágio produtivo e mudança estrutural”, tesis de doctorado en economía, Río de Janeiro, Universidad Federal de Río de Janeiro.

Costa, K. (2017), "Entre similaridades e diferenças nos padrões de comércio exterior e de estrutura produtiva do Brasil e do México: uma análise multissetorial a partir de matrizes de insumo-produto", tesis de doctorado en economía, Río de Janeiro, Universidad Federal de Río de Janeiro.

Costa, K., M. Castilho y M. Puchet (2018), "Structure productive et effet d'entraînements productifs à l'ère des chaînes globales de valeur: une analyse input-output", Revue d'Économie Industrielle, vol. 3, № 163.

Coutinho, L. (1997), "A especialização regressiva: um balanço do desempenho industrial pós-estabilização", Brasil: desafios de um país em transformação, J. Velloso (coord.), Río de Janeiro, José Olympio Editora.

Dietzenbacher, E. (1992), "The measurement of interindustry linkages: key sectors in the Netherlands", Economic Modelling, vol. 9, $\mathrm{N}^{\circ} 4$, octubre.

Durlauf, S. (2005), "Complexity and empirical economics", The Economic Journal, vol. 115, № 504, junio.

Finn, J. (1976), "Measures of ecosystem structure and function derived from analysis of flows", Journal of Theoretical Biology, vol. 56, № 2.

Fontana, M. (2008), "The complexity approach to economics: a paradigm shift", Working Paper, № 2008/01, Torino, Centro di Studi sulla Storia e i Metodi dell'Economia Politica "Claudio Napoleoni" (CESMEP).

Fujii, G. y R. Cervantes (2017), "The weak linkages between processing exports and the internal economy: the Mexican case", Economic Systems Research, vol. 29, № 4.

(2013), "México: valor agregado en las exportaciones manufactureras", Revista CEPAL, № 109 (LC/ G.2556-P), Santiago, Comisión Económica para América Latina y el Caribe (CEPAL).

(2012), "The Mexican trade liberalization process and its net effects on employment: 1988-2004", EconoQuantum, vol. 9, № 2.

Gazon, J. y M. Nihon (1976), Transmission de l'influence économique, une approche structurale, París, Sirey.

Guo, D., G. Hewings y M. Sonis (2005), "Integrating decomposition approaches for the analysis of temporal changes in economic structure: an application to Chicago's economy from 1980 to 2000", Economic Systems Research, vol. 17, № 3 .

Hausmann, R. y C. Hidalgo (2011), "The network structure of economic output", Journal of Economic Growth, vol. $16, \mathrm{~N}^{\circ} 4$, diciembre.

Hausmann, R., J. Hwang y D. Rodrik (2007), "What you export matters", Journal of Economic Growth, vol. 12, $N^{\circ} 1$, marzo. 
Hausmann, R. y otros (2014), The Atlas of Economic Complexity: Mapping Paths to Prosperity, Cambridge, The MIT Press.

Hermida, C. (2016), "Padrão de especialização comercial e crescimento econômico: uma análise sobre o Brasil no contexto da fragmentação da produção e das cadeias globais de valor", tesis de doctorado en economía, Uberlândia, Universidad Federal de Uberlândia.

Hewings, G. y otros (1998), "The hollowing-out process in the Chicago economy, 1975-2011", Geographical Analysis, vol. 30, № 3.

Hidalgo, C. y otros (2007), "The product space conditions the development of nations", Science, vol. 317, № 5837, Washington, D.C., Asociación Estadounidense para el Progreso de la Ciencia (AAAS).

Hirschman, A. (1961), La estrategia del desarrollo económico, Ciudad de México, Fondo de Cultura Económica.

Ibarra, D. y J. Moreno-Brid (2001), "Currency boards and monetary unions: the road ahead or a cul de sac for Mexico's exchange rate policy?", Mexico beyond NAFTA: Perspectives for the European Debate, M. Puchet y L. Punzo (eds.), Londres, Routledge.

Jensen, R. y G. West (1980), "The effect of relative coefficient size on input-output multipliers", Environment and Planning A: Economy and Space, vol. 12, № 6.

Kaldor, N. (1967), Strategic Factors in Economic Development, Ithaca, ILR Press.

Katz, J. (2000), Reformas estructurales, productividad y conducta tecnológica en América Latina, Santiago, Fondo de Cultura Económica/Comisión Económica para América Latina y el Caribe (CEPAL).

Kume, H. (1996), "A política de importação no plano real e a estrutura de proteção efetiva", Texto para Discussão, № 423, Río de Janeiro, Instituto de Investigación Económica Aplicada (IPEA), mayo.

Kupfer, D. (2005), "A indústria brasileira após a abertura”, Brasil em desenvo/vimento: economia, tecnologia e competitividade, A. Castro y otros (eds.), Río de Janeiro, Civilização Brasileira.

Kupfer, D. y otros (2013), "Different partners, different patterns: trade and labour market dynamics in Brazil's post-liberalisation period", OECD Trade Policy Papers, № 149, París, Organización de Cooperación y Desarrollo Económicos (OCDE).

Lantner, R. (1974), Théorie de la dominance économique, París, Dunod. (1972), "L'analyse de la dominance économique", Revue d'économie politique, vol. 82, № 2.

Lantner, R. y D. Lebert (2015), "L'input-output est mort? Vive l'analyse structurale!: Dominance et amplification des influences dans les structures linéaires", Économie Appliquée, vol. 68, № 3.

(2013), "Dominance, dependence and interdependence in linear structures: a theoretical model and an application to the international trade flows", CES Working Papers, № 43, París, Universidad de París.

Lantner, R. y F. Carluer (2004), "Spatial dominance: a new approach to the estimation of interconnectedness in regional input-output tables", The Annals of Regional Science, vol. 38, № 3, septiembre.

Lewis, W. (1958), Teoría del desarrollo económico, Ciudad de México, Fondo de Cultura Económica.

López, J. (1998), La macroeconomía de México: el pasado reciente y el futuro posible, Ciudad de México, Miguel Ángel Porrua.

Marcato, M. y F. Ultremare (2018), "Produção industrial e vazamento de demanda para o exterior: uma análise da economia brasileira", Economia e Sociedade, vol. 27, Nㅜㄹ, Campinas, Universidad Estadual de Campinas.

Marconi, N. (2015), "Estrutura produtiva e desenvolvimento econômico", Indústria e desenvolvimento produtivo no Brasil, N. Barbosa y otros (coords.), Río de Janeiro, Elsevier.

McMillan, M. y D. Rodrik (2011), "Globalization, structural change and productivity growth", NBER Working Paper, N 17143, Cambridge, Oficina Nacional de Investigaciones Económicas (NBER), junio.

Medeiros, C. y N. Trebat (2018), "Las finanzas, el comercio y la distribución del ingreso en las cadenas globales de valor: implicancias para las economías en desarrollo y América Latina", Estudios sobre financierización en América Latina, Libros de la CEPAL (LC/PUB.2018/3-P), M. Abeles, E. Caldentey y S. Valdecantos (eds.), Santiago, Comisión Económica para América Latina y el Caribe (CEPAL).

Medeiros, C., F. Freitas y P. Passoni (2019), "Structural change and the manufacturing sector in the Brazilian economy: 2000-2014", The Manufacturing Sector in Argentina, Brazil, and Mexico: Transformations and Challenges in the Industrial Core of Latin America, Palgrave Studies in Latin American Heterodox Economics, J. E. Santarcángelo (ed.), Cham, Palgrave Macmillan.

Moreno-Brid, J. y J. Ros (2010), Desarrollo y crecimiento en la economía mexicana: una perspectiva histórica, Ciudad de México, Fondo de Cultura Económica.

Peacock, A. y D. Dosser (1957), "Input-output analysis in an underdeveloped country: a case study", The Review of Economic Studies, vol. 25, N 1, octubre. 
Puchet, M. (1996), "Análisis de la integración económica: aspectos del caso EUA-México", La inserción internacional del MERCOSUR: ¿mirando al Sur o mirando al Norte?, L. Bizzozero y M. Vaillant (eds.), Montevideo, Arca.

Rasmussen, P. (1963), Relaciones intersectoriales, Madrid, Aguilar.

Robinson, S. y A. Markandya (1973), "Complexity and adjustment in input-output systems", Oxford Bulletin of Economics and Statistics, vol. 35, № 2, Oxford, Basil Blackwell.

Rodrik, D. (2006), "What's so special about China's exports?", China \& World Economy, vol. 14, № 5.

Romero, I., E. Dietzenbacher y G. Hewings (2009), "Fragmentation and complexity: analyzing structural change in the Chicago regional economy", Revista de Economía Mundial, № 23.

Ros, J. (2015), Grandes problemas: ¿cómo salir de la trampa del lento crecimiento y alta desigualdad?, Ciudad de México, El Colegio de México/Universidad Nacional Autónoma de México (UNAM). (1994), "Mexico's trade and industrialization experience since 1960: a reconsideration of past policies and assessment of current reforms", Trade Policy and Industrialization in Turbulent Times, G. Helleiner (ed.), Nueva York, Routledge.

Rosser, J. (2012), "Sobre las complejidades de la compleja dinámica económica", Las ciencias de la complejidad: vertiente dinámica de las ciencias de diseño y sobriedad de factores, W. González (ed.), La Coruña, Netbiblo/Universidad de A Coruña.

Rostow, W. (1959), "The stages of economic growth", The Economic History Review, vol. 12, № 1.

Ruiz-Nápoles, P. (2004), "Exports, growth, and employment in Mexico, 1978-2000”, Journal of Post Keynesian Economics, vol. 27, № 1.

Sarti, F. y C. Hiratuka (2018), "Desempenho recente da indústria brasileira no contexto de mudanças estruturais domésticas e globais", Para além da política econômica, R. Carneiro, P. Baltar y F. Sarti (coords.), São Paulo, Editora Unesp.

Simon, H. (1962), "The architecture of complexity", Proceedings of the American Philosophical Society, vol. $106, N^{\circ} 6$, diciembre.

Sonis, M. y G. Hewings (1998), "Economic complexity as network complication: multiregional input-output structural path analysis", The Annals of Regional Science, vol. 32, № 3, agosto.

Souza, K. y M. Castilho (2016), "Integração produtiva e acordos comerciais: o caso dos países da Aladi", Economia e Sociedade, vol. 25, № 1, Campinas, Universidad Estadual de Campinas.

Torracca, J. (2017), "Coevolução das estruturas de produção e comércio exterior da indústria brasileira: convergência ou desarticulação?", tesis de doctorado, Río de Janeiro, Universidad Federal de Río de Janeiro, mayo.

Ulanowicz, R. (1983), "Identifying the structure of cycling in ecosystems", Mathematical Biosciences, vol. 65, $\mathrm{N}^{\circ} 2$, agosto.

Wong, Y. (1954), "Some mathematical concepts for linear economic models", Economic Activity Analysis, O. Morgenstern (ed.), Nueva York, John Wiley \& Sons.

Yan, C. y E. Ames (1965), "Economic interrelatedness", The Review of Economic Studies, vol. 32, № 4, octubre. 